\title{
MULHERES NA POLÍTICA PARTIDÁRIA: ALGUNS ETHOS DE ATUAÇÃO DE PREFEITAS PARAIBANAS
}

\author{
Cosma Ribeiro de Almeida ${ }^{1}$
}

Resumo: O objetivo deste trabalho é refletir sobre os elementos culturais, historicamente arraigados na educação social brasileira, presentes na atuação de prefeitas paraibanas. Entendemos que tal educação não formal contribui para a reprodução de comportamentos tidos como hegemônicos e responsáveis pela assimetria ente homens e mulheres. Para isso, foram entrevistadas em 2015, cinco prefeitas eleitas em 2012, em que as mesmas relatavam a condição do ser "mulher política" ao mesmo tempo em que colocavam seus anseios e ansiedades diante de um espaço considerado distante para o gênero feminino. Concluímos que apesar de tentarem construir uma identidade própria de mulher política, muitas acabam reproduzindo a política do machismo e do patriarcalismo no exercício da gestão pública ao afirmarem alguns ethos de atuação como "o ser guerreira" e "o ser forte". Isso se dá principalmente porque muitas delas pertencem a famílias políticas da Paraíba e tentam construir uma "identidade própria” do ser mulher política.

Palavras chave: Política. Mulher política. Prefeitas. Paraíba.

\section{WOMEN IN PARTY POLITICS: SOME ETHOS OF ACTING OF PARAIBAN MAYORS}

\begin{abstract}
The aim of this paper is to reflect on the cultural elements, historically rooted in Brazilian social education, present in the performance of Paraíba mayors. We understand that such non-formal education contributes to the reproduction of behaviors considered hegemonic and responsible for the asymmetry between men and women. For this, five mayors elected in 2012 were interviewed in 2015, in which they reported the condition of being a "political woman" while placing their anxieties and anxieties in front of a space considered distant for women. We conclude that although they try to build their own identity as a political woman, many end up reproducing the politics of machismo and patriarchalism in the exercise of public management by affirming some ethos of action as "being warrior" and "being strong". This is mainly because many of them belong to Paraíba political families and try to build a "self-identity" of being a political woman.
\end{abstract}

Keywords: Politics. Political woman. Mayors. Paraíba.

\section{Introdução}

\footnotetext{
${ }^{1}$ Doutora em Ciências Sociais pela Universidade Federal de Campina Grande - UFCG. Contato: cosma_almeida@yahoo.com.br
} 
Revista NEP - Núcleo de Estudos Paranaenses, Curitiba, v. 5, n. 2, dez. 2019

As percepções das prefeitas sobre a política partidária nos revelam um conjunto simbólico que envolve a posição da mulher na sociedade culturalmente. A condição da mulher política e as imagens que tentam projetar no exercício do mandato revelam uma determinada prática "típica do fazer feminino", como, por exemplo, "o ser guerreira", "o ser forte", que contraria uma certa identidade da mulher na sociedade como "incapaz para a política", incapaz para atividades "extra-masculinas", dentre outros.

Entendemos, com base nas falas de prefeitas paraibanas, que ao exercer o cargo público, estas mulheres mobilizam muitas ordens típicas da condição cultural das mulheres cujas características que evocam são geralmente semelhantes, tais como: o cuidar, o ser mãe do povo, estar perto do outro, tutelar o próximo.

Neste sentido, é de suma importância entender as experiências do feminino a partir das ritualidades de suas práticas e discursos. Ora, se o exercício da política não acontece pelo mundo da força física ela se realiza pela força simbólica (SFEZ apud BARREIRA, 1998). A realidade e o conjunto simbólico são partes de um todo, não existem de forma separada, pois evocam uma prática cultural enraizada socialmente. Esse rito tenta provocar, muitas vezes, a separação entre o lugar da política e o lugar privado, embora os elementos da tradição surjam nas falas das prefeitas de forma "espontânea" denunciando o ritual que as colocam na posição tradicional do ser "mulher política".

Considerando a herança como o processo de transmissão de um patrimônio de uma geração à outra, ou de uma pessoa a outra [...] as práticas de transmissão de herança podem dizer muito a respeito da cultura e da forma como o poder é distribuído na sociedade (RABAY, 2012, p. 64).

Com base nestas assertivas, nossa análise se detém às falas de entrevista com cinco prefeitas paraibanas eleitas em $2012^{2}$. Decidimos não mencioná-las no texto nem a cidade onde foram eleitas, portanto são referidas no presente artigo como prefeita 1, 2, 3, 4 e 5.

Nossa metodologia é de cunho descritiva e exploratória, cuja abordagem se dá no universo da pesquisa qualitativa (CHIZZOTTI, 2009), momento em que a pesquisadora busca os valores morais, as subjetividades, a realidade os quais as entrevistadas fazem parte.

\footnotetext{
${ }^{2}$ As entrevistas pessoais ocorreram em 2015 nas cidades onde as prefeitas exerciam o cargo público.
} 
Revista NEP - Núcleo de Estudos Paranaenses, Curitiba, v. 5, n. 2, dez. 2019

Para tanto, é possível perceber de forma semelhante "qualidades femininas" que marcam a presença delas na política e que, portanto, aqui tratamos como rituais para se fazer apresentar: o discurso da diferença e o afeto propagado pelo sentimento. Estes apontam de forma semelhante a percepção e a ação destas prefeitas na política paraibana. O que fortalece por outro lado os homens na política, os mesmos pelos quais elas fazem parte do jogo, das estratégias, pois muitas ocupam o cargo que exerce por meio deles ${ }^{3}$.

\section{O ser "guerreira", o ser "forte"}

Para a reflexão sobre o ethos na política é pertinente a teoria de Patrick Charaudeau (2006). Para ele, ethos são atribuições positivas que os políticos "se vestem" na atuação ou preparação para a política formal a fim de conquistar o público eleitor. Entendemos que as prefeitas enfrentam fortes valores morais do espaço da política como se fosse especificamente o espaço do masculino, cujo lugar é como se não pertencesse às mulheres e sim aos homens.

Neste sentido, para se fazerem apresentar na política formal muitas mulheres transferem práticas do espaço privado para o público, de forma consciente ou não. Sob este prisma de serem capazes de enfrentar as "barreiras" culturais dizem que são intituladas pelos eleitores, e se auto intitulam, de "guerreiras". Como sinônimo de mulher que enfrenta os desafios, que não desiste, "que vai à luta".

Ser "guerreira" constitui, neste caso, um símbolo de credibilidade. Uma representação cujo significado é positivo no espaço público. Este rendeu a uma das prefeitas tal título como reconhecimento do seu trabalho: intitulada de "guerreira" pelos eleitores, condicionada pelas estratégias políticas familiares e grupos de interesses políticos, transfere o "título de guerreira" para sua única filha, considerada por ela como a futura mulher política da cidade em que é gestora. Assim, ressalta: "a guerreira surgiu na reeleição, já chamam minha filha de 'guerreirinha'. Trabalhei muito, as pessoas é quem chamavam" (Prefeita 2). Na ocasião da entrevista, ao falar de reeleição, lembra que foi bem sucedida nas duas campanhas eleitorais, tendo em vista que foi reeleita e o povo já espera que sua filha se candidatasse para continuar a política da mãe.

\footnotetext{
${ }^{3}$ Muitas mulheres se candidatam ao pleito municipal quando o pai, o esposo ou o tio não pode mais se candidatar. Surge, assim, uma oportunidade para tais mulheres adentrar no universo da política formal.
} 
Revista NEP - Núcleo de Estudos Paranaenses, Curitiba, v. 5, n. 2, dez. 2019

Além de "guerreira", qualidades como o "bem" e a "verdade" são ressaltadas como típicos da mulher política. Ambos corroboram para a construção de uma imagem pública positiva que se diferencia da imagem masculina, por exemplo. Pois estas representariam a honestidade, o respeito e a ética.

Por outro lado, é possível observar que trata-se de qualidades culturalmente "próprias" ao universo masculino: adjetivos como guerreira, fortaleza, coragem, revelam atributos culturais do homem e não da mulher (SWARTZENBERG, 1987). Na tentativa de se revestirem com tais atributos, talvez, as mulheres tentem se projetar melhor para o mundo da política, pois uma vez aceitas pelo povo mostrariam que estavam preparadas para o espaço que as tornariam legítimas governar e teriam a "capacidade de serem prefeitas".

A titulação "guerreirinha" seria uma confirmação de prestígio pelo mandato que exerceria. Portanto, tal adjetivo confirmaria na visão da prefeita, por exemplo, a "coragem" que culturalmente é um símbolo de força restrito aos homens e não às mulheres, mas que agora uma mulher teria também tal "qualidade".

Tais preconceitos que enfrentam permitem às prefeitas um maior impulso para discutir ou enfrentar aquilo que chamam de empecilhos na política, uma delas diz o seguinte:

Teve um momento que a gente tava fazendo um momento aqui na comunidade de Aparecida, eu e outra pessoa que hoje é Secretário nosso de Obras, e eles (adversários) foram para lá e nos intimidaram de forma que não deixavam que nós saíssemos da casa que nós estávamos visitando, e nos rodearam de maneira agressiva. E foi preciso até a gente chamar meu irmão para ele levar outras pessoas para a gente poder continuar fazendo as visitas. Que eles estavam ameaçando. Com mulher era muito mais fácil fazer isso, que a força física do homem é muito maior do que a nossa, não tem nem comparação né (Prefeita $5)$.

A fala demonstra indícios de discriminação que a prefeita sofreu tanto nos momentos em que ainda era candidata como nos momentos de exercício do poder público. Demonstra que é capaz de superar tais preconceitos ocasionados pelos adversários, que a intitulava de "mulher frágil" e sem afinidade com a prática política.

Apesar da decisão em disputar um cargo público de gestão municipal, por influência dos companheiros ou familiares, pleiteou o cargo demonstrando uma superação da presença em um espaço de poder ocupado majoritariamente por homens. 
Pois, declara enfrentamento ao poder masculino predominante na política da cidade, e que culturalmente apenas homens haviam assumido a prefeitura do município antes dela, sendo portanto a primeira mulher a ocupar o cargo de prefeita daquela cidade.

Da mesma forma acontece com outra gestora municipal que ao mencionar que sofreu muitos preconceitos não "desanimou", pois quanto mais superava os desafios mais tinha vontade de vencê-los: "Eles desrespeitam de todo jeito. O desrespeito era nos comícios. Diziam que eu não tinha graduação, que eles eram doutores" (Prefeita 2). Na tentativa de minimizar a imagem pública da mulher política que não tem diploma, os políticos e "doutores" do município utilizou da velha prática política de assistencialismo ou clientelismo, ou seja, coagir os eleitores através de trocas de favores e passar a mensagem de que os melhores representantes da política seriam eles mesmos e não a adversária que "sequer tem um diploma e não é doutora".

Percebe-se que para cada região, através de um contexto sociocultural específico, é revelada nas falas das prefeitas uma competição que girava em torno da capacidade de liderança. O ser “doutor”, por exemplo, é cogitado pelos adversários como uma qualidade indispensável para o candidato ser eleito. Em algumas cidades do Estado paraibano, principalmente no interior, a figura do "doutor" simboliza a imagem do poder tradicional e comando da região. Mas, "falar a verdade, ter um passado limpo, ser dedicada e estar presente" (Prefeita 2) são alguns dos discursos da prefeita como uma espécie de "armadura" utilizada no combate político.

“A inexperiência política pode, assim, tornar-se virtude", pois a não prática nos âmbitos do poder colocam a mulher, muitas vezes, em um patamar distante das espúrias do poderio político formal (BARREIRA, 1998, p. 106). Ou seja, uma vez não tendo experiência na política formal ou partidária, isto se revelaria como um atributo positivo, pois as mulheres não tendo "conhecimento" da gestão pública poderia demonstrar que não pertencia às astúcias da política tal como a corrupção, por exemplo.

Muitas vezes a falta de uma extensa participação ou experiência na política formal pode surgir como um fenômeno positivo para as mulheres. A prefeita 1 evidencia a imagem do político como personagem importante do poder. Aquele que carrega uma bateria de valores morais, culturais, religiosos, e é visto pelos eleitores de forma diferente, como um "salvador". Ao se referir a si própria como figura pública, diz o seguinte: 
[...] Muitos veem você como um artista. Guarda sua foto em casa na moldura, ela beija, coloca o santinho perto, faz como se você fosse uma pessoa muito querida. A minha foto junto com a de um santo, junto com a família. No guarda - roupa ele (eleitor) coloca a foto, quer dizer ele idealiza muito como artista. Quando você chega junto dele (eleitor) é uma honra, um prestígio. (Prefeita 1).

Para Patrick Charaudeau (2006) a palavra que o (a) político (a) pronuncia deve ser entendida pelo que ele (a) diz ou não. Deve ser compreendida como uma estratégia, pois as maneiras de ser determinam as ideias, os comportamentos. Para isso, muitas vezes o político assume um determinado ethos para se fazer representar.

O ethos político é resultado de uma alquimia complexa feita de traços pessoais de caráter, de corporalidade, de comportamentos, de declarações verbais, tudo relacionado às expectativas vagas dos cidadãos por meio de imaginários que atribuem valores positivos e negativos a essas maneiras de ser. Toda construção do ethos se faz em uma relação triangular entre si, o outro e o terceiro ausente, portador de uma imagem ideal de referência: o si procura endossar essa imagem ideal; o outro se deixa levar por um comportamento de adesão à pessoa que a ele se dirige por intermédio dessa mesma imagem ideal de referência (CHARAUDEAU, 2006, p. 137).

Assim, a imagem da prefeita comparada a um artista, ou seja, como uma pessoa muito importante, diferente dos demais indivíduos, nos faz remeter ao ethos de competência, este seria capaz de proporcionar tal qualidade. “Às vezes, o próprio político que evidencia em suas declarações as características de seu percurso para invocar esse ethos de 'competência': herança, estudos, funções exercidas, experiências adquiridas" (CHARAUDEAU, 2006, p. 124).

A presença das mulheres na política está submetida a vários rituais que se revelam por meio de símbolos, geralmente, dotados de características "naturalizadas" por elas mesmas e tendo como reciprocidade o comportamento das pessoas nas ruas. A exemplo da prefeita (Prefeita 3) quando relaciona a sua gestão ao ethos de seriedade. Esse ethos é construído a partir de vários elementos, sejam expressões corporais, comportamentos que

revelam capacidade de autocontrole diante das críticas, sangue-frio diante da adversidade, não se entregar a acessos de cólera nem mostrar que é contida (na verdade calculada) com objetivos táticos; índices que demonstram grande energia e capacidade de trabalho, onipresença em todas as linhas de frente da vida política e social, particularmente junto àqueles que sofrem (CHARAUDEAU, 2006, p. 120). 
A prefeita (Prefeita 3) menciona o plano de atividades que pretende realizar, os programas que almeja, o que nos revela um sentimento de enfrentamento dentro de uma mesma dinâmica de valoração da gestão pública. A prefeita evoca, concomitantemente, a união da coletividade para o bem comum, marcando suas expressões pela constituição de um imaginário coletivo, que diante da realidade de crise em que se encontra o país e o município é necessário determinado controle e cuidado no modo de fazer política.

Para isso, na visão da gestora também é necessário que o político tenha virtude para assumir o cargo público, assim como ela própria em algumas declarações enfatiza: "Pelo que você pressentiu eu sou muito desenrolada, dinâmica. Ai, então, eu não podia ver tantos desmandos, tanta coisa desmantelada" (Prefeita 3).

\footnotetext{
O ethos de virtude é igualmente necessário ao político, pois se supõe que ele, como representante do povo, é quem dá o exemplo. Esse ethos exige que o político demonstre sinceridade e fidelidade, a que se deve acrescentar uma imagem de honestidade pessoal (CHARAUDEAU, 2006, p. 122).
}

Ao lembrar "eu tenho o cuidado, eu tenho a sensibilidade", a prefeita demonstra a virtude e a tentativa de fidelidade para com a gestão municipal, acrescenta-se neste sentido uma honestidade pessoal que deve anteceder a prática política.

\begin{abstract}
Dizer o que se pensa, ter uma vida transparente (nada ter a esconder), não ter participado de negócios escusos e mostrar que seu engajamento político não foi motivado por uma ambição pessoal. Essa honestidade pode igualmente exprimir-se em relação aos adversários em termos de lealdade: aquele que combate seu oponente sem jamais desferir golpes baixos e que, em caso de derrota, é capaz de reconhecer a validade do julgamento do outro e mesmo seus próprios erros (CHARAUDEAU, 2006, p. 123).
\end{abstract}

Nesta performance também se aproxima ao ethos de competência, deixa clara a tentativa de que "os políticos devem mostrar que conhecem todas as engrenagens da vida política e que sabem agir de maneira eficaz" (CHARAUDEAU, 2006, p. 124). A prefeita, em muitos momentos durante a sua fala, justifica suas ações sociais e públicas declarando "inocência" enquanto gestora, mesmo que perguntas sobre gestão pública especificamente sobre ações de governo não tenham sido feitas ou cogitadas durante a entrevista. Ao mencionarmos as qualidades que a identificam como prefeita, sugere um ethos de competência: "Vivo na cidade, vivo a comunidade, sou a delegada, a polícia, o padre, o médico, a enfermeira, o psicólogo, portas abertas. (...) Mas você se mostra amiga, parceira, dedicada". 
Revista NEP - Núcleo de Estudos Paranaenses, Curitiba, v. 5, n. 2, dez. 2019

Ora, por que é o padre? O médico? A política? O psicólogo? Não se trata de ser apenas a prefeita? Assumindo todos estes cargos não estaria assumindo a postura de uma prefeita de assistencialismo social para angariar eleitores? Não estaria sendo tradicional em suas práticas e entrando em contradição com o que diz e defende? Agindo desta forma, a prefeita marca sua trajetória de gestora pública municipal com as práticas da política masculinizada da região, tendo em vista que busca conquistar as pessoas da cidade de uma maneira mais simples e "barata" pelas astúcias do poder político formal.

Patrick Charaudeau (2006) sobre o ethos de competência diz o seguinte:

O ethos de competência exige de seu possuidor, ao mesmo tempo, saber a habilidade: ele deve ter conhecimento profundo do domínio particular no qual exerce sua atividade, mas deve igualmente provar que tem os meios, o poder e a experiência necessários para realizar completamente seus objetivos, obtendo resultados positivos (CHARAUDEAU, 2006, p. 124).

Como afirma Patrick Charaudeau (2006) é pela visão de conjunto que se pode creditar competência ou não ao político. Questionada sobre como gostaria de ser reconhecida pelos seus eleitores a prefeita assevera: "Como amiga, irmã amiga. Apesar de que no começo fui vista como forasteira. Por que vim de fora, não fui filha da cidade, mas agora sou vista como irmã, companheira, que é a forma do meu comprometimento" (Prefeita 3).

A representação simbólica presente nesta fala nos leva a perceber os valores que conformam a valorização do ser político em determinado contexto social e local, ou seja, a moral que eiva o cotidiano da prática política. Assim, a prefeita continua dizendo o seguinte: "Eu tenho muito respeito pelas pessoas. Muito respeito. Eu tenho um principio de vida que é interessante, eu faço para você o que eu não gostaria de receber, posso estar muito irritada mas não faço, por que a "roda gira" (Prefeita 3 ).

Ao mencionar a "roda gira" é o mesmo que dizer "a gente não sabe o dia de amanhã": hoje prefeita, amanhã não se sabe. As pessoas são interdependentes, por isso que as relações sociais são muito importantes para que um indivíduo possa se manter em uma determinada posição social, principalmente a posição social do poder. Para isso, alimentar a relação com os eleitores ou com o povo é uma tarefa pertinente para a execução do poder político e a permanência nele. Segundo a prefeita, o prestígio 
conquistado como prefeita "amiga do povo" garantiu através da "transparência" o equilíbrio na aceitação de sua imagem política.

A proximidade com as pessoas nas ruas, sejam elas jovens, crianças ou adultos, é um dos símbolos relevantes em que a prefeita também comunga com as visões de mundo da população e conhece a realidade de perto dentro do seu contexto. Neste sentido, a ação política é simbólica, pois é através da cultura, da rede de significados, em que esta política se concretiza.

Nesta aproximação com o povo, a política utiliza de alguns recursos simbólicos e conquista, muitas vezes, a atenção do outro, a exemplo do sentimento. Este passa a ser um dos principais elementos em comum das prefeitas paraibanas aqui estudadas e passa a ser um eixo de relações que se mantém atualizado durante a gestão pública.

Mesmo sem ser questionada sobre tal atitude a prefeita se sente à vontade para falar dos seus sentimentos enquanto pessoa, enquanto mulher, mas também enquanto prefeita. Tudo isso perpassa nas intenções da prefeita que não deseja separar o "ser humano" do "ser político", a ponto de não se considerar uma mulher política mas sim uma administradora:

Em certas situações não digo nem que sou Prefeita. Me qualifico como administradora. No passado a prefeitura era usada com muito poder, eu não, administradora. Eu estou aqui. Tem gente que até fala: "e ai num vai ter reeleição não?" (Prefeita 3).

E complementa:

(...) Minha abertura é falar, é convencer, é reunir. É dizer "me ajude, vamos pensar juntos". Aqui não tem palavra de rei não. Se eu perceber que eu estou errada, eu volto atrás imediatamente. Peço desculpas, parabenizo, e peço desculpas, quando eu erro eu peço desculpas. E quando faz certo eu parabenizo, e faço com que as pessoas vejam isso também. Por que aquela pessoa também se sente valorizada (Prefeita 3).

No contexto de falar sobre a presença da mulher na política, concorda com as ideias de que as mulheres precisam "se mostrar mais" e perder o medo de entrar na política formal: "Nós temos que despertar o interesse da mulher na política. Elas não se impõem, não se arriscam. Por que?" (Prefeita 3).

Ora, essa experiência das prefeitas concerne àquilo que está organizado socialmente, principalmente ao governo do espaço público. O que define a característica 
das prefeitas é partilha da esfera privada (instância cidadã) com a esfera pública (ideal de sociedade). Os sentimentos de cidadania são propostos pelas prefeitas, a idealização de uma sociedade resulta em conflitos.

(...) O objeto de busca da ação política é um "bem soberano" que une essas duas instâncias em um pacto de reconhecimento de um "ideal social" que é preciso querer atingir e para cuja obtenção é preciso dar-se os meios. A tarefa do discurso político é, portanto, determinar, de acordo com seu propósito, esse ideal dos fins como busca universal das sociedades (CHARAUDEAU, 2006, p. 189).

As representações simbólicas, portanto, aqui explicitadas nos ajudam a interpretar a realidade e as atribuições de suas significações. Tais significados são entendidos a partir do conjunto de crenças, de conhecimentos e comportamentos, produzidos e compartilhados por estas prefeitas. Este grupo social permite ritualidades e projeções de signos que dizem muito sobre sua vivência no espaço público.

\section{Considerações finais}

É importante registrar que as considerações finais estão limitadas a um determinado objeto de estudo restrito a um tempo e espaço: prefeitas eleitas em 2012. As falas das prefeitas demonstram que naquele período em que eram prefeitas e assumiam uma postura de gestora pública, seus ethos correspondia a uma demanda e necessidade do momento.

O ethos da competência, da força, da eficácia, denuncia a necessidade dessas mulheres se mostrarem além do que aparentam ser: apenas mulheres. Mas mulheres fortes, com capacidade de assumir um cargo público, isto lhe custara um preço alto devido a sobrecarga psicológica que as atingiam, fazendo com que se "desdobrassem" para mostrar uma capacidade tanto quanto a do homem, por exemplo. Pois, algumas diziam da relação com o parentesco na política, mas desejavam demonstrar autonomia política.

Esta assimetria do homem e da mulher na política deixa claro que as mulheres precisam assumir uma postura da eficiência pública, da virtude política, porque ao adentrar no universo partidário percebem-se que todas as suas características são masculinas, ou seja, valores de mundo "pertencente ao homem". Para desmitificar esta 
Revista NEP - Núcleo de Estudos Paranaenses, Curitiba, v. 5, n. 2, dez. 2019 Dossiê Oligarquias do Nordeste no Brasil

ISSN: 2447-5548

ideia, utilizam -se do ethos da coragem, da garra, para sobressair-se e tentar construir uma identidade política própria. O que de fato acabam contribuindo para a reprodução do poderio político na Paraíba, tendo em vista que não demoram na política partidária e veem uma grande dificuldade para isto.

\section{REFERÊNCIAS BIBLIOGRÁFICAS}

BARREIRA, Irlys Alencar Firmo. Chuva de Papéis: ritos e símbolos de campanhas eleitorais no Brasil. Rio de Janeiro. Relume Dumará: Núcleo de Antropologia Política, 1998.

CHARAUDEAU, Patrick. Discurso político. São Paulo, Contexto, 2006.

CHIZZOTTI, Antônio. Pesquisa em ciências humanas e sociais. 10 ed. São Paulo: Cortez, 2009.

RABAY, Glória. CARVALHO, Maria Eulina Pessoa de. Mulher e Política na Paraíba: História de vida e luta. João Pessoa: Editora Universidade da UFPB. 2010.

SCHWARTZENBERG, Roger-Gérard. O Estado Espetáculo. Rio de Janeiro: Difel, 1978.

Recebido em: 31 out. 2019

Aceito em: 26 nov. 2019 